\title{
0 lugar da Antropologia na formação docente: um olhar a partir das Escolas Normais
}

\author{
Amurabi de Oliveira*
}

\section{Resumo}

O presente trabalho busca problematizar a relação entre Antropologia e Educação, a partir de uma discussão histórica, envolvendo a fundação dos primeiros gabinetes de Antropologia Pedagógica na primeira metade do século XX, almejando, desse * Professor do Centro de Educação da Universidade Federal de Alagoas (UFAL), Brasil. modo, repensar a própria história da Antropologia brasileira, destacando o lugar que ela ocupou no processo de formação de professores no Brasil. Destaca-se ainda a relação entre o movimento da "Escola Nova", a perspectiva higienista e esta Antropologia Pedagógica aqui desenvolvida.

\section{Palavras-chave}

Antropologia Pedagógica; história da Antropologia; formação de professores; Escola Nova 


\title{
The role of anthropology in teachers' training: a perspective from the schools for teachers' education
}

\begin{abstract}
This paper raises raises some questions on the relationship between anthropology and education from a historical perspective, involving the foundation of the first "offices of pedagogical anthropology" in the first half of the twentieth century, aiming thereby to rethink the history of Brazilian anthropology, highlighting the place anthropology occupied with the process of teacher formation in Brazil. Another highlight is the relationship between the movement of the "New School", the hygienist perspective and this pedagogical anthropology developed here.
\end{abstract}

Key words Pedagogical Anthropology; history of Anthropology; teacher formation; new school movement 


\title{
Ideias iniciais
}

Ao pensarmos o percurso da ciência antropológica no Brasil, remetemo-nos, inevitavelmente, a seu processo de institucionalização no decorrer dos anos 30 do século XX, período em que são fundadas a Escola Livre de Sociologia e Política de São Paulo (1933) e a Universidade de São Paulo (1934). Segundo Miceli (1989), é nesse momento que as Ciências Sociais passam, no Brasil, por um momento de profissionalização, sendo, em princípio, um projeto acadêmico essencialmente paulista. Melo (1999), por exemplo, ao sintetizar a história da Antropologia no Brasil, realiza os seguintes apontamentos:

\begin{abstract}
Ainda que a história da antropologia no Brasil recue ao final do século passado, com as pesquisas do médico baiano Nina Rodrigues, é usual ressaltarem, em sua cronologia, alguns marcos: o desenvolvimento da etnologia indígena - Darcy Ribeiro foi o fundador do Museu do Índio -; a publicação de Casa Grande e Senzala, de Gilberto Freyre, em 1993, inaugurando a chamada "antropologia da sociedade nacional"; 0 trabalho desenvolvido no Museu Nacional, a partir dos anos 30, por Luiz de Castro Faria e outros antropólogos; a reunião de fundação da Associação Brasileira de Antropologia - ABA, em 1953; e, por fim, a criação do Programa de Pós-Graduação em Antropologia Social do Museu Nacional, em 1968. (Melo, 1999, p. 214).
\end{abstract}

Contudo, é emblemático que as Ciências Sociais no Brasil passem a se difundir, ainda na passagem do século XIX para o XX, inicialmente, por um contingente de intelectuais autodidatas, em sua maioria, empenhados no processo de sistematização do conhecimento dessas ciências no País (Meucci, 2011), envolvendo tanto figuras notórias do campo científico brasileiro, como Fernando Azevedo, Amaral Fontoura, Amoroso Lima, Delgado de Carvalho, Gilberto Freyre, dentre outros, como autores menos conhecidos, que se empenharão na produção de manuais de Ciências Sociais, especialmente de Sociologia, entre os anos de 1920 e 1940, principalmente.

Em meio a esse cenário, consideramos fundamental destacar o lugar das Escolas Normais no processo de fomento e sistematização do conhecimento antropológico no Brasil, por meio da ideia de produção de uma "Antropologia Pedagógica", o que conflui com a ideia, defendida por Gusmão (1997), de que a interface entre a Antropologia e a Educação não constitui uma invenção recente. Acreditamos que compreender a história e o desenvolvimento da Antropologia no Brasil, em especial a Antropologia 
Pedagógica, nos remete, inevitavelmente, ao debate estabelecido ao longo das duas primeiras décadas do século XX, em especial nas Escolas Normais. Também se mostra relevante, nesse processo, a análise do impacto da chamada Escola Nova no contexto intelectual e educacional brasileiro, a qual afetou diretamente as reformas educacionais vivenciadas no País nesse período.

Nossa finalidade com este trabalho é lançar um novo olhar sobre a interface entre a Antropologia e a Educação, bem como sobre a própria história da Antropologia no Brasil, refletindo acerca do lugar desta ciência no processo de formação docente, em especial a partir das Escolas Normais.

\section{Antropologia e normalistas}

Para que iniciemos nossa reflexão em torno do lugar da Antropologia na formação docente no Brasil, devemos, primeiramente, remeter-nos a sua própria constituição como campo específico, o que nos leva à formação das Escolas Normais no decorrer do século XIX. Como nos aponta Saviani (2011), a formação do campo pedagógico brasileiro se atrela de forma visceral às ações dos jesuítas no Brasil e da Igreja Católica, de modo mais geral. Apenas com as reformas pombalinas, cujos influxos se estenderam por aqui de 1759 a 1834, é que esse cenário passa a ser modificado, por intermédio, principalmente, das chamadas aulas régias. Estas “[...] se contrapõem ao predomínio das ideias religiosas e, com base nas ideias laicas inspiradas no iluminismo, instituem o privilégio do Estado em matéria de instrução" (Saviani, 2011, p. 114). Chamam a atenção, em meio a tais reformas, a estatização e a secularização do magistério, organizando exames como mecanismo de controle e condição do exercício docente. Enxergamos aí um primeiro passo no processo de profissionalização do trabalho docente, que vai desembocar na criação das primeiras Escolas Normais no Brasil, em Niterói, no ano de 1835; e na Bahia, em 1842.

Claro que a constituição dessas Escolas não se deu de forma linear no Brasil: durante as reformas promovidas por Couto Ferraz, no decorrer dos anos 50 do século XIX, as Escolas Normais foram fechadas e, em substituição a elas, criou-se a figura dos professores adjuntos. A ideia que norteava tal ação seria a formação na prática, o que não se sustentou por muito tempo, tendo ocorrido, posteriormente, a reabertura de muitas dessas Escolas.

Interessa-nos destacar que tais instituições adentram o século XX como principais formadoras de professores, passando pelo período do Império e da República que 
se inicia, de tal modo que elas não ficarão imunes ao discurso positivista assentado numa enorme fé na ciência, como promotora do Brasil. Educação e Ciências estariam intimamente ligadas, de modo que, para muitos intelectuais desse período, a Educação se mostra como caminho para a redenção do atraso brasileiro (Botelho, 2002).

No bojo das reformas implementadas nas primeiras décadas do século XX, todo o sistema de ensino será reformado, sendo emblemáticas a criação e a difusão dos grupos escolares na passagem do século XIX para o XX (Souza, 2006). As transformações vivenciadas na educação básica ensejaram também mudanças nas Escolas Normais, pois o novo professor deveria estar preparado para executar sua nova missão. Segundo Nagle (1974, p. 219):

A escola normal vai experimentar profundas transformações durante o período que está sendo estudado; na verdade, da mesma forma que aconteceu com a escola primária, a "moderna" escola normal vai se estruturar nesse tempo. [...]

No período, e além disso, se processa a profissionalização do curso normal, quando se define um conteúdo de preparo técnico pedagógico, principalmente pela inclusão, no plano de estudos, de disciplinas como anatomia e fisiologia humanas, pedagogia, história da educação, sociologia e, especialmente, psicologia.

Percebemos, nesse momento, uma especial atenção à formação profissional nesses espaços, o que ocorreu pela difusão das matérias pedagógicas, em detrimento de outras, voltadas para a formação geral, representando, segundo Meucci (2011), uma revolução intelectual que visava fornecer uma formação científica para os professores.

Contudo, essa revolução intelectual não se articulou apenas pela inclusão de novas disciplinas no currículo das Escolas Normais: devemos destacar o desenvolvimento, em tais instituições, de práticas experimentais que visavam consolidar essa formação científica para o professorado. É importante também a fundação, em 1909, do Gabinete de Antropologia Pedagógica e Psicologia, na cidade de Amparo, por Clemente Quaglio, que visava buscava investigar o desempenho das faculdades intelectuais das crianças, articuladamente com o trabalho escolar (Monarcha, 1999). Nesse cenário: 
A antropologia pedagógica e a psicologia experimental concretizadas por Quaglio assentam no clima normalista da belle époque: a ideia de medida, os temas patológicos e a classificação dos tipos mediante utilização dos procedimentos analíticos e experimentais. A objetivação desse clima empenhado em expurgar os contornos fluidos da pedagogia coloca em atividade a operação analítica, decompondo a figura acabada e explicando suas partes constituintes, para reordená-las artificialmente, comparando o indivíduo com o todo. (Monarcha, 1999, p. 255)

Este panorama será reforçado com a criação, em 1914, do Gabinete de Psicologia e Antropologia Pedagógica da Escola Normal da Praça, em São Paulo, pelo médico-pedagogista Ugo Pizzoli, que se voltaria para a observação do homem com critérios naturalistas, marcadamente um laboratório que possuía como referência o positivismo italiano. Seus procedimentos estavam amplamente assentados nas proposições de Lombroso, de modo que nos estamos referindo, nesse período, principalmente a uma vertente da Antropologia Física (Sganderla; Carvalho, 2008), o que convergia com algumas ideias defendidas pelos pensadores sociais e da Educação no Brasil naquele momento. Segundo Freitas (2005, p. 62-63, grifo do autor):

Na metade do século XX, no Brasil, intelectuais de variados jaezes ainda apontavam a necessidade de associar à prática docente informações provenientes de "laboratórios de antropologia" que alguns centros de pesquisa tinham a oferecer ao trabalho escolar. Contudo, é necessário distinguir usos e abusos da antropologia. Na realidade, em retornando àqueles debates, não se constata a reedição das práticas antropométricas tais quais as que acompanharam, por exemplo, a atuação de Nina Rodrigues em Salvador ou de Ugo Pizzoli na cidade de São Paulo e que subsidiaram várias decisões relacionadas à vida da criança na escola.

Cabe-nos, aqui, um primeiro ponto de reflexão mais sistemática sobre a razão de ter sido essa passagem da história da Antropologia brasileira olvidada pelos antropólogos. $\mathrm{O}$ fato de estarmos aqui nos referindo a uma Antropologia Física é significativo para que tal questão seja esclarecida, uma vez que essa ciência se distancia dos paradigmas instaurados pela Antropologia Social e Cultural, que se tornam dominantes 
no campo acadêmico brasileiro (Oliveira, 2012), sendo mesmo combatida, por vezes, por estas. Não à toa, Durham e Cardoso (1961, p. 96) apontam para as dificuldades do ensino de Antropologia Física, que se restringiria “[...] apenas a informações gerais e, quando muito, a uma caracterização dos problemas centrais da disciplina, que complementam uma formação voltada para as Ciências Sociais".

Ainda que haja tensões postas entre essas diversas vertentes da Antropologia, interessa-nos aqui que a interface entre a Antropologia e a Educação se mostre fundamental para a compreensão do próprio desenvolvimento desta ciência no Brasil, de modo que não podemos encará-la como um pedaço menor da história da Antropologia brasileira. Encontramos aí um cenário de institucionalização da Antropologia, voltado para o processo formativo de professores, que antecede sua presença nas universidades. Desse modo, pensar a Antropologia brasileira é pensar sua íntima relação com a Educação e com o processo formativo docente, ainda que possamos problematizar a abordagem adotada nesse momento. Esse contexto se tornará ainda mais complexo com o advento da Escola Nova e das questões que esta traz para o debate educacional brasileiro.

\section{A Antropologia Pedagógica e a Escola Nova}

O Manifesto dos Pioneiros da Escola Nova, publicado em 1932, que teve como mentor intelectual a figura de Fernando Azevedo (Xavier, 2002), deixou marcas profundas na Educação brasileira, proclamando a necessidade de reconhecer a educação como função pública, sendo responsabilidade do Estado. Ainda que haja interpretações profundamente díspares com relação a seu caráter conservador ou revolucionário (Cunha, 1994; Cury, 1988, 2004; Nagle, 1974; Nunes, 1991; Saviani, 2009; Silva, 2002), é inegável o seu impacto no campo educacional brasileiro.

Nessa direção, apontamos duas questões trazidas pela Escola Nova que, em nossa interpretação, convergem para as questões postas pela Antropologia Pedagógica nesse período: a crença no método científico aplicado à Educação e a ideia do direito biológico à educação, ambas profundamente imbricadas.

É válido ressaltar o contexto em que o manifesto é produzido, embebido em meio aos debates fomentados pela Associação Brasileira de Educação - ABE -, de que católicos e liberais participavam. A ruptura entre tais grupos possui como marco a publicação do referido manifesto, cuja redação partiu da provocação do governo Vargas, que havia acabado de criar o Ministério da Educação e Saúde Pública, chefiado por Francisco Campos, 
por ocasião da IV Conferência Nacional de Educação, realizada de 13 a 20 de dezembro de 1931. Esse encontro exortou os educadores que dele participavam a definir as bases da política educacional que deveriam guiar as ações do governo. Destaca-se, nesse documento publicado em 1932, além da defesa de que a educação deveria se tornar uma função essencialmente estatal - estando aí um dos principais, se não o principal, ponto de divergência com o grupo católico da $A B E$-, o fato de que ao educador caberia munir-se de métodos científicos, em oposição a um “empirismo grosseiro”, para impulsionar a administração dos serviços escolares (Saviani, 2011). Para Cury (1988, p. 182-183, grifos do autor): "Se os católicos defendiam o messianismo católico, os "Pioneiros", em geral participantes da estrutura governamental, defendiam o messianismo científico".

No que tange ao direito biológico à educação, os Pioneiros buscavam substituir a concepção tradicional, que serviria aos interesses de classe, por uma outra, baseada no caráter biológico, que permitiria a cada sujeito educar-se "até onde o permitam as suas aptidões naturais, independente de razões de ordem econômica e social" (Manifesto dos Pioneiros da Escola Nova, 1932). Nesse sentido, Veiga (2004, p. 68) destaca “[...] a pouca atenção dada na historiografia da Escola Nova à influência dos ideários higienistas e teorias eugênicas na difusão das práticas escolanovistas" e ainda acrescenta:

Podemos dizer que a escola republicana é a escola-vetor da medicalização, onde os alunos se configuravam como objetos de experimentação, nos quais médicos, engenheiros, juristas e educadores exerceram os seus ensaios de modernidade. A produção da concepção do cidadão e da cidadania esteve subjugada a padrões científicos de normalidade ou não-normalidade física e mental. (Veiga, 2004, p. 73).

Essa perspectiva já está presente nos trabalhos de Quaglio, que, em 1911, a pedido do Diretor Geral Instrução Pública, realiza, com os alunos do Grupo Escolar do Carmo e do Jardim de Infância, anexo à Escola Normal da Praça, um estudo sobre o desenvolvimento da infância anormal, aplicando as técnicas, então existentes, da Antropologia Pedagógica e da Psicologia Experimental (Monarcha, 1999).

Também nessa mesma direção, destaca-se a pesquisa intitulada “Contribuição à antropologia da moça mineira”, desenvolvida em 1933 por Julia de Magalhães Viotti, sob a orientação de Helena Antipoff, professora de Psicologia Experimental na Escola de Aperfeiçoamento de Minas Gerais. A pesquisa se organiza em duas partes: 
os dados morfológicos dos pesquisados e os dados antropométricos, e envolve 101 mulheres; porém, para o estudo de raça, a amostra é de 50, todas alunas-professoras da Escola de Aperfeiçoamento de Minas Gerais.

A pesquisa converge para um conjunto de ideias difundidas, entre os anos de 1920 e 1930, em torno de um mestiçamento positivo, em que se espera que a sociedade brasileira se torne cada vez mais branca (Schwarcz, 1993). Viotti busca averiguar se as observações in loco confirmarão ou não os dados do inquérito, chegando à conclusão de que há uma reduzida mestiçagem, em oposição a um elevado grau de "arianização" do grupo pesquisado.

Tais pesquisas se difundem nas chamadas Escolas Normais, como pode ser atestado pela defesa da tese de Luiz Ignácio de Andrade, intitulada "Um aspecto regional de antropologia escolar", defendida em 1941, para o provimento da cadeira de Antropologia Pedagógica da Escola Normal de Pernambuco. E, no mesmo ano, com "Fundamentos biotipológicos da Educação", Valdemar de Figueiredo Valente, busca se tornar professor catedrático de Antropologia Pedagógica na Escola Normal Oficial de Recife.

No ideário da Escola Nova, essas pesquisas no âmbito da Antropologia Pedagógica poderiam contribuir para a consolidação de uma hierarquia democrática, tendo por base as capacidades individuais biológicas. Numa crítica a essa posição, Cury (1988, p. 186) aponta que

a seletividade, apenas baseada nas condições intelectuais e biológicas do educando, parece-nos ingênua enquanto realiza o papel da infra-estrutura, justamente quando foram os próprios Pioneiros que enfatizam o econômico na caracterização do industrialismo. Além do mais, os caracteres bio-intelectuais são socialmente condicionados pela posição de classe do indivíduo.

Cabe-nos, portanto, problematizar a utilização de tais procedimentos investigativos presentes nessa Antropologia Pedagógica, neste momento, por mais que devamos reconhecer que, mesmo assentada em técnicas antropométricas e em um ideal higienista, essa Antropologia busca, em última instância, conhecer o outro; saber quem ele é, ainda que possamos problematizar como se deu esta construção do “outro".

O que está em questão é como formar professores e como eles lidariam com os sujeitos envolvidos no universo escolar. É, portanto, uma necessidade conhecer esses sujeitos, saber quem são. A partir do ideário da Escola Nova, a ciência será o principal 
recurso para tanto, que possibilitará a formação de professores não mais baseada em simples "empirismo", que seria o substrato principal do método tradicional, sendo este, portanto, pré-científico, ou mesmo anticientífico, tese contestada por Saviani em Escola e democracia (2009).

Ainda que tal discurso encontre mais ressonância na primeira metade do século XX, chama-nos a atenção que, ainda nos anos de 1960-70, encontremos ecos dessa Antropologia Pedagógica que se pretende experimental. A publicação, no Brasil, de Antropologia e Educação (1963), coletânea de textos organizada por Frederick C. Gruber, apenas dois anos após sua publicação nos Estados Unidos, aponta para essa direção. Logo no prefácio de tal obra, são anunciados seus objetivos:

0 principal objetivo da educação em qualquer sociedade é salvaguardar a sua continuidade. A natureza da escola, uma das principais forças educacionais da sociedade, é, por consequência, determinada pela natureza da própria sociedade: os seus ideais nacionais, as relações entre os cidadãos e o Estado e a sua atitude em relação à infância. Para que se tenha uma compreensão mais nítida de uma complexa sociedade pluralista, como a nossa, onde os conceitos são muitas vezes mal interpretados é bom considerar as influências da educação em grupos sociais menos sofisticados. Os conhecimentos de Antropologia são da maior utilidade no estudo deste assunto, porque se relacionam com as manifestações biológicas e psíquicas da vida humana, tal como se apresentam nas diferentes raças e nas diversas sociedades. (Gruber, 1963, p. 13).

Claramente se revela aí presente uma perspectiva instrumental da Antropologia, ainda assentada na crença de que esta, como ciência, pode trazer elementos que contribuam para a compreensão do espaço escolar e de seus sujeitos, por meio da aplicação de determinadas técnicas. Nessa mesma direção, em 1970, René Ribeiro publica o artigo "Aplicação da sociometria à didática da Antropologia”, no qual reconhece a classe escolar como um "sistema social em miniatura", que, portanto, possuiria uma estrutura própria, de modo que a Antropologia poderia lançar mão de recursos para a análise desse sistema social, considerando a sociometria, o que poderia vir a auxiliar no trabalho docente. Para Ribeiro (1970, p.92-93, grifo do autor), a elaboração de sociogramas por parte do professor poderia ser útil da seguinte forma: 
É óbvio que para um professor reger adequadamente uma classe necessita de conhecer individualmente a seus alunos. Essa individualização dos membros da classe é obtida instantaneamente, quando da elaboração dos sociogramas ao ponto de poder o professor, na aula seguinte, identificar a quase todos eles e chamá-los principalmente aos líderes, por seus nomes de batismo. Em segundo lugar, conhecidos os indivíduos de maior prestígio e os sub-grupos em que se divide a classe (e uma experiência interessante é verificar como se distribuem sempre os alunos no espaço físico da sala de aulas conforme ao padrão traçado no sociograma) torna-se fácil ao professor dispensar atenção a cada um desses núcleos em particular, durante as preleções, dividir tarefas e fixar responsabilidades quando da ministração de aulas práticas, ou quando da realização de trabalhos-de-grupo.

Percebamos aí que se mantém uma perspectiva em que a Antropologia pode trazer contribuições para o debate pedagógico por meio de uma instrumentalização científica, ainda que, nesse período, as questões postas pela Antropologia Social e Cultural já estejam bastante difundidas no Brasil.

O que nos interessa aqui é destacar a singularidade dessa Antropologia Pedagógica, que em muito dista da Antropologia que se institucionaliza nas universidades brasileiras a partir dos anos de 1930; contudo, mostra-se fundamental para a compreensão da interface entre a Antropologia e a Educação e também para a própria reelaboração da história da Antropologia brasileira, que tende a olvidar esse momento de produção do conhecimento no âmbito antropológico. Mesmo no período da década de 1950, em que há uma forte presença de cientistas sociais no aparato estatal e, portanto, envolvidos no debate público, o que inclui aí o debate educacional, há um apagamento dessa interface entre a Antropologia e a Educação. Acerca desse ponto, Correa (1988, p. 14, grifo do autor) nos elucida:

Não acredito que as razões do esquecimento deste período tão interessante da história de nossa disciplina se devam apenas à descrença no tipo de antropologia que se fazia antes de hoje ou à alegada fragilidade institucional dela naquele momento; penso antes que esse esquecimento deve ser atribuído ao fato de que tentamos buscá-la onde ela não podia estar, num "campo antropológico" ainda em constituição, ao invés de encontrá-la lá onde ela se praticava. 
Este artigo buscou, pelo contrário, procurar a Antropologia onde ela estava, ou seja, nas Escolas Normais, no campo educacional, na formação de professores. Acreditamos, portanto, que há necessidade de reescrever a própria história da Antropologia brasileira, desenvolvendo essa escrita a partir da interface com a Educação.

\section{Considerações finais}

Este breve artigo procurou lançar um olhar sobre a Antropologia Pedagógica não só para uma melhor compreensão do campo da Antropologia da Educação no Brasil, atualmente, como para um melhor entendimento da própria Antropologia brasileira como um todo.

Ainda que os métodos antropométricos amplamente utilizados nos primeiros Gabinetes de Antropologia Pedagógica possam ser largamente criticados, assim como a perspectiva higienista reforçada pela Escola Nova, acreditamos que precisamos tanto compreender tais elaborações dentro do seu próprio tempo, como também reconhecer aí um primeiro esforço aproximativo, no exercício de conhecer "o outro".

Mais que isso, parece-nos de fundamental relevância destacar aqui o reconhecimento que a Antropologia alcançou na primeira metade do século XX, como ciência necessária para o processo formativo de professores. Tal processo se mostra sempre desafiador, pois, por vezes, a Antropologia não é percebida como tendo uma finalidade prática, ao se inserir nos currículos de formação de professores, como já apontaram Durham e Cardoso em 1961. Contudo, devemos destacar que

\footnotetext{
a antropologia nos permite, neste sentido, analisarmos criticamente o lugar do outro, inclusive o lugar do outro na construção de nossa própria subjetividade, elemento primordial para nos apropriarmos criticamente do fazer educacional. (Oliveira, 2012, p. 130).
}

Muitos paradigmas mudaram na Antropologia brasileira desde a fundação do Gabinete de Psicologia e Antropologia Pedagógica na Escola Normal da Praça; contudo, o "outro" continua a ser um grande desafio, em especial no universo escolar, e certamente, nesse ponto, a Antropologia ainda é capaz de nos trazer nossos olhares, nossas possibilidades de compreensão desse outro e de nós mesmos. 


\section{Referências bibliográficas}

BOTELHO, A. Aprendizado do Brasil: a nação em busca dos seus portadores sociais. Campinas, SP: Editora da Unicamp, 2002.

CORREA, M. A revolução das normalistas. Cadernos de Pesquisa - Fundação Carlos Chagas, São Paulo, n. 66, ago. 1988.

CUNHA, L. A. Educação e classes sociais no Manifesto de 32: perguntas sem respostas. Revista da Faculdade de Educação da USP, São Paulo, v. 20, n. 1-2, p. 132-150, jan./dez. 1994 .

CURY, C. R. Ideologia e educação brasileira: católicos e liberais. São Paulo: Cortez, 1988.

CURY, C. R. Um olhar sobre o Manifesto dos Pioneiros da Educação Nova de 1932. In: XAVIER, M. C. (Org.). Manifesto dos Pioneiros da Educação: um legado educacional em debate. Rio de Janeiro: FGV, 2004.

DURHAM, E. R.; CARDOSO, R. C. L. O ensino de Antropologia no Brasil. Revista de Antropologia, São Paulo, v. 9, n. 1-2, p. 91-108, 1961.

FREITAS, M. C. Alunos rústicos, arcaicos \& primitivos: o pensamento social no campo da educação. São Paulo: Cortez, 2005.

GRUBER, F. C. (Org.). Antropologia e Educação. Rio de Janeiro: Fundo de Cultura, 1963. GUSMÃO, N. M. M. Antropologia e educação: origens de um diálogo. Cadernos CEDES, Campinas, v. 43, p. 8-25, 1997.

MANIFESTO DOS PIONEIROS DA ESCOLA NOVA. 1932.

Disponível em: http://www.pedagogiaemfoco.pro.br/hebo7a.htm.

MELO, M. P. C. Quem explica o Brasil. Juiz de Fora: Editora UFJF, 1999.

MEUCCI, S. Institucionalização da sociologia no Brasil: primeiros manuais e cursos. São Paulo: Hucitec; Fapesp, 2011.

MICELI, S. História das Ciências Sociais no Brasil. São Paulo: Vértice, 1989.

MONARCHA, C. Escola Normal da Praça: o lado noturno das luzes. Campinas, SP: Editora da Unicamp, 1999.

NAGLE, J. Educação e sociedade na Primeira República. São Paulo: EDUSP, 1974.

NUNES, C. Anísio Teixeira: a poesia da ação. 1991. Tese (Doutorado em Educação) - Faculdade de Educação, Pontifícia Universidade Católica do Rio de Janeiro, Rio de Janeiro. OLIVEIRA, A. Antropologia e antropólogos, educação e educadores: o lugar do ensino de Antropologia na formação docente. Percursos - UDESC, Florianópolis, v. 13, p. 120132, 2012. 
RIBEIRO, R. Aplicação da sociometria à didática da antropologia. Revista do Instituto de Filosofia e Ciências Humanas, Rio de Janeiro, v. 1, n.1, jan./jun. 1970.

SAVIANI, D. Escola e democracia. Campinas: Autores Associados, 2009.

SAVIANI, D. História das ideias pedagógicas no Brasil. Campinas: Autores Associados, 2011.

SCHWARCZ, L. M. O espetáculo das raças: cientistas, instituições e questão racial no Brasil, 1870-1930. São Paulo: Companhia das Letras, 1993.

SGANDERLA, A. P.; CARVALHO, D. C. Lourenço Filho: um pioneiro da relação entre psicologia e educação no Brasil. Psicologia da Educação, São Paulo, n.26, p. 173-19o, 2008.

SILVA, G. M. D. Sociologia da Sociologia da Educação: caminhos e desafios de uma Policy Science no Brasil (1920-1979). Bragança Paulista: Edusf, 2002.

SOUZA, R. F. Espaço da educação e da civilização: origens dos grupos escolares no Brasil. In: SAVIANI, D. et al. (Org.). O legado educacional do século XIX. Campinas: Autores Associados, 2006.

VEIGA, C. G. Manifesto dos pioneiros de 1932: o direito biológico à educação e a invenção de uma nova hierarquia social. In: XAVIER, M. C. (Org.). Manifesto dos pioneiros da educação: um legado educacional em debate. Rio de Janeiro: Editora FGV, 2004.

VIOTTI, J. Contribuição à antropologia da moça mineira. In: SECRETARIA DE EDUCAÇÃO E SAÚDE PÚBLICA/INSPETORIA GERAL DE INSTRUÇÃO PÚBLICA. Boletim, Belo Horizonte, n. 13, 1933.

XAVIER, L. N. Para além do campo educacional: um estudo sobre o Manifesto dos pioneiros da educação nova (1932). Bragança Paulista: Edusf, 2002.

Submetido à publicação em 10 de janeiro de 2013.

Aprovado em 08 de março de 2013. 